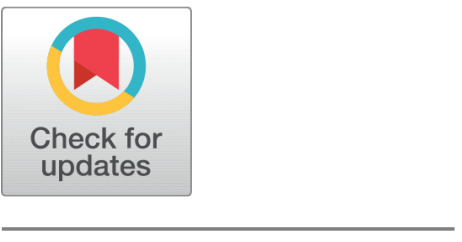

OPEN ACCESS

Received: 12.05 .2021

Accepted: 02.08.2021

Published: 07.09.2021

Citation: Surve ML, Unde SS, Sutar KB, Dhurpate $P$, Kumbhar DG (2021) Computational Studies on Airfoil for Micro-Capacity Horizontal Axis Wind Turbine. Indian Journal of Science and Technology 14(29): 2427-2438. https://doi.org/ 10.17485/IJST/v14i29.824

* Corresponding author.

kbsutar@bvucoep.edu.in

Funding: None

Competing Interests: None

Copyright: (c) 2021 Surve et al. This is an open access article distributed under the terms of the Creative Commons Attribution License, which permits unrestricted use, distribution, and reproduction in any medium, provided the original author and source are credited.

Published By Indian Society for Education and Environment (iSee)

ISSN

Print: 0974-6846

Electronic: 0974-5645

\section{Computational Studies on Airfoil for Micro-Capacity Horizontal Axis Wind Turbine}

\author{
Minendra L Surve ${ }^{1}$, Sanket S Unde ${ }^{1}$, Kailasnath B Sutar ${ }^{1}{ }^{*}$, \\ Priyanka Dhurpate ${ }^{1}$, Dnyaneshwar G Kumbhar ${ }^{1}$ \\ 1 Department of Mechanical Engineering, Bharati Vidyapeeth (Deemed to be University), \\ College of Engineering, Pune-Satara Road, Katraj, Pune, 411043, India
}

\section{Abstract}

Objectives: To design a blade profile suitable for a micro-capacity wind turbines. To analyze the performance of a new blade profile in terms of lift to drag ratio using simulation software such as QBlade and ANSYS Fluent CFD. Methods: A new airfoil for a micro capacity horizontal axis wind turbine is designed using QBlade software. A 3D model of the airfoil is prepared using CATIA. 2D and 3D CFD simulations of this airfoil are carried out using ANSYS Fluent and the simulation results are compared with those obtained from QBlade. Findings: It is found that QBlade results for the lift to drag ratio fairly match with the experimental results at all values of angles of attack $\left(0^{\circ}\right.$ to $\left.20^{\circ}\right)$. 3D CFD results also fairly match with experimental results at lower values of angles of attack $\left(0^{\circ}\right.$ to $\left.3^{\circ}\right)$. The optimum value of lift to drag ratio is obtained for the angle of attack of $3^{\circ}-4^{\circ}$. 3D CFD simulation under predicts lift to drag ratio at higher angles of attack as compared to the experimental values. Novelty: The study reports simulation results for an airfoil blade profile of a micro-capacity wind turbine using both QBlade and ANSYS Fluent CFD (both 2D and 3D). The simulation results fairly match with the available experimental results.

Keywords: airfoil; microcapacity; wind turbine; lift to drag ratio; angle of attack; CFD

\section{Introduction}

As of March 2021, the total renewable energy installed capacity of India is $91.15 \mathrm{GW}$, which is $24.5 \%$ of the total installed capacity generated from renewable as well as nonrenewable sources of energy ${ }^{(1)}$. In wind power installation, India has ranked $4^{\text {th }}$ with an installed capacity of $38.62 \mathrm{GW}$ till $31^{\text {st }}$ December $2020^{(2)}$. According to the capacity of power generation, the wind turbines are classified as micro $(50 \mathrm{~W}-2 \mathrm{~kW})$, small (2.1 $\mathrm{kW}-40 \mathrm{~kW})$, medium ( $40.1 \mathrm{~kW}-999 \mathrm{~kW})$, large (1 MW - $6 \mathrm{MW})$ and ultra large (above $6 \mathrm{MW})^{(3)}$. Some researchers found that large-capacity wind turbine farms may lead to significant weather changes ${ }^{(4,5)}$. To avoid this, the use of micro to small capacity wind turbines for domestic application is proposed by the researchers ${ }^{(6)}$. Bukala et al. ${ }^{(7)}$ reported that Weibull or Rayleigh probability distributions give better estimates of wind energy generation as compared to those obtained using the yearly wind 
speed of the location. The authors also advocated for investment in robust, cheap, and simple turbine design. Lee et al. ${ }^{(8)}$ performed experimental and computational studies of the baseline blade and the blade designed using Blade Element Momentum Theory (BEMT). It was found that as compared with the baseline blade, the maximum power coefficients of the BEMT-blade increased by more than $50 \%$. Here, power coefficient refers to the ratio of electrical power output to the wind energy input. Betz's limit for maximum power coefficient of any wind turbine is $0.593^{(9)}$. Rodrigues et al. ${ }^{(10)}$ reported guidelines for the development of small wind turbines using scrap material. Sing and Ahmed ${ }^{(11)}$ designed a new airfoil and tested the performance of two-bladed rotors at a wind speed range of 3-6 m/s at a height of $8.22 \mathrm{~m}$. The maximum power coefficient at free stream velocity of $6 \mathrm{~m} / \mathrm{s}$ was 0.29 . Ali et al. ${ }^{(12)}$ reported that winglet has a significant effect on the performance of domestic size horizontal axis wind turbines and the upwind winglet increases lift to drag ratio by about $26 \%$ as compared to straight blades. Pourrajabian et al. ${ }^{(13)}$ used a genetic algorithm optimization technique to optimize the chord and twist of wind turbines with capacities of $0.5 \mathrm{~kW}, 0.75 \mathrm{~kW}$, and $1 \mathrm{~kW}$. Also, the effect of a number of blades, resistive torque, and starting wind speed was studied. Ozgener ${ }^{(14)}$ reported the performance of a $1.5 \mathrm{~kW}$ capacity small wind turbine system with a rotor diameter of 3 $\mathrm{m}$ placed at a height of $12 \mathrm{~m}$ above the ground level. At an average wind speed of $7.5 \mathrm{~m} / \mathrm{s}$, the turbine produced electricity of $616 \mathrm{~W}$. Ameku et al. ${ }^{(15)}$ reported design of a $3 \mathrm{~kW}$ wind turbine with three blades of a thin airfoil. At a wind speed of $10 \mathrm{~m} / \mathrm{s}$ and power coefficient of 0.14 , an average generator output of $1105 \mathrm{~W}$ was found. Xie et al. ${ }^{(16)}$ tested three innovative blades in the low-speed wind tunnel and found that when the outer blade section was folded, there was a decrease in both blade conversion efficiency and power coefficient. Monteiro et al. ${ }^{(17)}$ performed wind tunnel testing of a horizontal axis wind turbine rotor and compared experimental results with two blade element momentum codes. Both experimental and numerical results were closely matching. Tummala et al. ${ }^{(6)}$ conducted an extensive review of literature on small-scale wind turbines and found that there is a scope for conducting a study of the effect of airfoil on the performance of wind turbines. To design a small wind turbine proper selection of airfoil and optimum design of rotor blades is mandatory ${ }^{(9)}$. Choubey et al. ${ }^{(18)}$ conducted CFD analysis on an airfoil (NACA0018) at different angles of attack (AOA) viz. $0^{\circ}, 10^{\circ}, 15^{\circ}$ and $30^{\circ}$ with a wind velocity of $4 \mathrm{~m} / \mathrm{s}$ and found that blade angle of $10^{\circ}$ gives optimal power. Ani ${ }^{(19)}$ found that hybrid PV/wind system shows better results in terms of Net Present Cost (NPC) and impact on the environment as compared to gasoline generator to power a household system. Reddy \& Rao ${ }^{(20)}$ reported the performance of Maximum Power Point Tracking (MPPT) based wind-solar hybrid power system. The authors used MATLAB Simulink software for performing the analysis. Surve ${ }^{(21)}$ conducted an extensive review of literature on horizontal axis wind turbine for domestic application. The author explained about blade design theories and reported that QBlade ${ }^{(22)}$ is a very essential tool for design and analysis of wind turbine blades. Dhurpate et al. ${ }^{(23)}$ reported that QBlade is a cost effective tool for simulation of newly designed airfoil. Pourrajabian et al. ${ }^{(24)}$ reported comparative study on material for wind turbine blade using four categories of timbers viz. alder, ash, beech and hornbeam. Multi-objective optimization technique was used to find material of blade suitable for a small wind turbine application, both in solid and hollow blade category. Alder was found to be the best timber suitable as a blade material at different speeds, in solid as well as hollow blade categories. Birajdar et al. ${ }^{(25)}$ designed two new airfoils for blades of a small wind turbine with blade length of $1.5 \mathrm{~m}$. The airfoil viz. IND 15045 was used at root section of the blade while the airfoil IND 09848 was used for the remaining section of the blade towards a tip. The authors described parameters for selection of a new wind turbine blade and also discussed various aerodynamic losses like tip, hub and drag etc. Khalil et al. ${ }^{(26)}$ performed 2D CFD simulation of airfoil using various models like inviscid, laminar, k- $\omega$ and Spalart-Allmaras. Among these models, k- $\omega$ and Spalart-Allmaras models showed accurate results when compared with those obtained using Blade Element Momentum (BEM) theory. This result highlights importance of consideration of appropriate turbulence model while performing CFD simulation of wind turbine blades. Tasneem et al. ${ }^{(27)}$ reported the current status of urban wind farm technology. The authors advocated for more investigation on wind mapping and suitable design of wind turbines for making urban wind farm technology as a sustainable decentralized energy generation option. Bangga ${ }^{(28)}$ reported performance of wind turbine of $10 \mathrm{MW}$ capacity using two simulation methods viz. CFD and BEM. It was found that accuracy of BEM approach depends on selection of polar data.

From the review of literature on wind turbines it is found that computational studies on design of blade profiles is very important step in actual development of the blades. In the present work, a new airfoil is designed by the authors using QBlade software $^{(22)}$. Performance of the designed airfoil is analyzed using QBlade software as well as by ANSYS CFD simulation software. The results obtained by both methods are compared.

\section{QBlade Simulation of New Airfoil}

For wind speed data of the Pune region, a new airfoil (INDTH1293) is designed by the authors using QBlade software (Figure 1). This software is used to design airfoils as per the requirements of the user. Wind turbine blades are designed in QBlade as per the designed airfoil cross-sections and aerodynamic performance of the blades is simulated. The working model of QBlade also provides information on variation in lift to drag ratios with angles of attack and also provides theoretical power generation 
capacity of the designed blades. The new airfoil has maximum thickness of $12.93 \%$ of chord length at $28.30 \%$ of the chord. And maximum thickness of camber is $4.76 \%$ of chord length at $46.30 \%$ of the chord. The designed airfoil is analyzed for different parameters like lift coefficient, drag coefficient, thrust, and power coefficient. The simulation is carried out for wind speed of $12 \mathrm{~m} / \mathrm{s}$ at Reynolds number $\mathrm{Re}=500000$. The angles of attack (AOA) range from $0^{\circ}$ to $20^{\circ}$, for different tip speed ratios (TSR). Here, tip speed ratio refers to the ratio of linear velocity of tip of the blade to average wind velocity. Mass density and kinematic viscosity of air are $1.225 \mathrm{~kg} / \mathrm{m}^{3}$ and $1.647 \times 10^{-5} \mathrm{~m}^{2} / \mathrm{s}$ respectively at an ambient temperature of $300 \mathrm{~K}$ and pressure of 1 atmosphere.

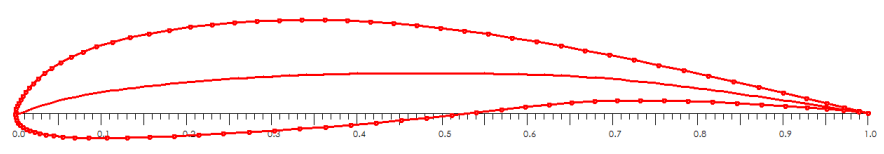

Fig 1. A new designed airfoil INDTH1293

\subsection{QBlade Simulation Results}

Power coefficient versus tip speed ratio plot gives an idea about extraction of power at different tip speed ratios (Figure 2). TSR varies from 0 to 10 . This ratio depends on various parameters such as number of blades, aerofoil design and type of turbine. It is cleared that at $\lambda=0$ there is no power extraction from the wind as the rotor does not rotate. There is an optimum TSR $(\lambda=$ 7) at which a maximum power coefficient of 0.53 is observed which is less than Betz's limit (0.593).

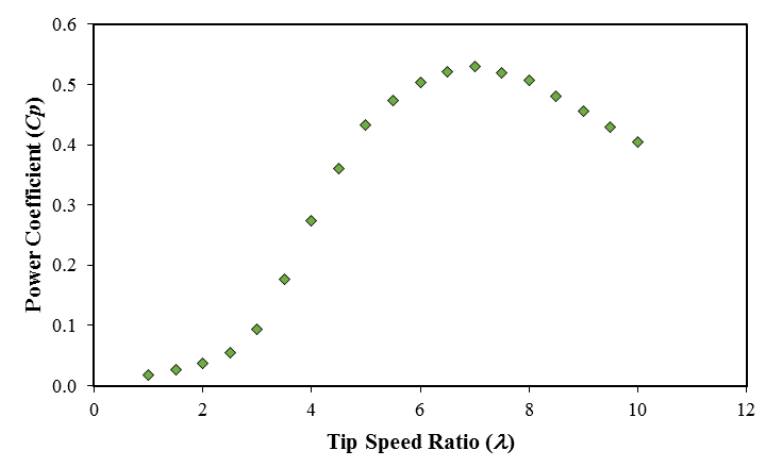

Fig 2. Power coefficient $\left(C_{p}\right)$ versus tip speed ratio $(\lambda)$

Figure 3 presents a plot of thrust coefficient $\left(\mathrm{C}_{T}\right)$ versus TSR. Thrust coefficient is the ratio of actual thrust available at the rotor to the maximum thrust produced by the wind. With the increase in TSR, the thrust coefficient also increases. This is due to an increase in thrust force on account of increased blade length. At a given wind velocity $\left(\mathrm{u}_{\infty}\right)$, TSR increases with increase in tip speed, which is directly proportional to blade length. At TSR $=7$, the value of the thrust coefficient is 0.78 .

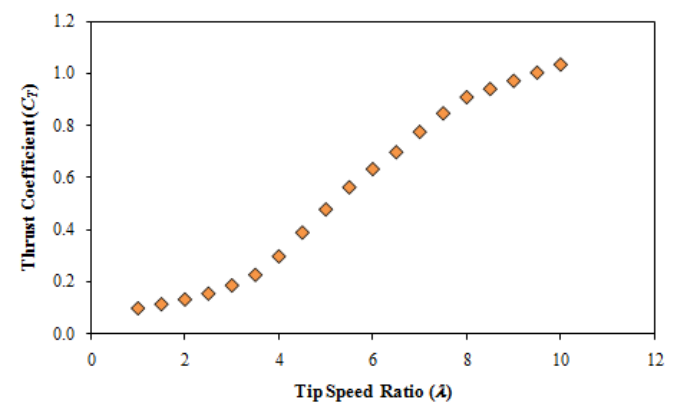

Fig 3. Thrust coefficient $\left(\mathrm{C}_{T}\right)$ versus tip speed ratio (l) 


\section{Two Dimensional (2D) CFD Simulation of an Airfoil}

In the present work, computational analysis is carried out using ANSYS Fluent CFD software ${ }^{(29)}$, wherein the equations for conservation of mass, momentum, and energy of flow of fluid are mathematically described by the partial differential equations (PDEs). To solve this fluid flow problem computationally, the PDEs are converted into algebraic equations using suitable numerical techniques. Here, the physical domain is divided into a large number of control volumes, called elements or cells. The three fundamental governing equations are solved with respect to fluid domain, boundary conditions, and type of flow.

\subsection{Governing equations used for CFD analysis}

Following governing equations are used in the CFD analysis of airfoil for blade of a wind turbine ${ }^{(25)}$.

Equation for conservation of mass i.e. continuity equation:

$$
\frac{\partial \rho}{\partial t}+\nabla \cdot(\rho \bar{U})=0
$$

Equation (1) is the mass conservation or continuity equation applicable for an unsteady, three-dimensional and compressible fluid. The first term on the left-hand side is the rate of change in time of the density (mass per unit volume). The second term describes the net flow of mass out of the element across its boundaries and is called the convective term.

For steady incompressible fluid flow, the first term in equation (1) is neglected. Then, equation (1) reduces to:

$$
\nabla \cdot(\rho \bar{U})=0
$$

In Cartesian notation, equation (2) can be written as:

$$
\frac{\partial u}{\partial x}+\frac{\partial v}{\partial y}+\frac{\partial w}{\partial z}=0
$$

Equation for conservation of momentum:

$$
\frac{\partial(\rho \bar{U})}{\partial t}+\rho(\bar{U} \cdot \nabla) \bar{U}=-\nabla p+\nabla \cdot \overline{\bar{\sigma}}+\rho \bar{f}_{b}
$$

In equation (4), $\overline{\bar{\sigma}}$ is the stress tensor for Newtonian viscous fluid, $\bar{f}_{b}$ represents body forces, i.e. gravity. At steady state, the first term in equation (4) will be zero. Hence, equation (4) reduces to:

$$
\rho(\bar{U} \cdot \nabla) \bar{U}=-\nabla p+\nabla \cdot \overline{\bar{\sigma}}+\rho \bar{f}_{b}
$$

\subsubsection{Turbulence modelling}

In the present analysis, turbulent fluid flows are considered. Modelling of turbulent flows is performed using Reynolds Averaged Navier Stokes equations (RANS). The RANS equations are time-averaged equations of motion for fluid flow. RANS are turbulence models that are used to predict the effects of turbulence in fluid flow without resolving all scales of the smallest turbulent fluctuations ${ }^{(30)}$.

Researchers have used different types of models for the analysis of the turbulent flow viz. k-e, k- $\omega$, SST and Spalart-Allmaras. $\mathrm{k}-\omega$ model works near the wall region where as $\mathrm{k}$-e model predicts performance far from the boundary region. The k-e, $\mathrm{k}-\omega$ are two equation models. SST is the combination of k-e and k- $\omega$ models. A one-equation model called Spalart-Allmaras solves a transport equation for eddy viscosity or turbulent viscosity. This model was designed mainly for aerospace applications involving wall-bounded flows. This model has shown good results for boundary layers subjected to large pressure gradients ${ }^{(31)}$. Hence, it is selected for the present computational analysis.

Spalart-Allmaras model is written in terms of eddy viscosity. This model includes eight closure coefficients and three closure functions. Its defining equations are as follows ${ }^{(29)}$ :

Eddy viscosity equation:

$$
\frac{\partial(\rho \tilde{v})}{\partial t}+\frac{\partial\left(\rho \tilde{v} U_{i}\right)}{\partial x_{i}}=G_{v}+\frac{1}{\sigma_{\tilde{v}}}\left[\frac{\partial}{\partial x_{j}}\left\{(\mu+\rho \tilde{v}) \frac{\partial \tilde{v}}{\partial x_{j}}\right\}+C_{b 2} \rho\left(\frac{\partial \tilde{v}}{\partial x_{j}}\right)^{2}\right]-Y_{v}+S_{\tilde{v}}
$$


Where $\mathrm{v}$ is the molecular kinematic viscosity, $\widetilde{v}$ is turbulent kinematic viscosity, $G_{v}$ is the production of turbulent viscosity, $Y_{v}$ is the destruction of turbulent viscosity that occurs in the near-wall region due to wall blocking and viscous damping $\sigma_{\widetilde{v}}$ and $C_{b 2}$ are the constants and $S_{\widetilde{v}}$ is a user-defined source term. For steady flow, the first term in equation (6) is neglected.

\subsection{Steps involved in CFD simulation}

- Create 2D Model

- Create mesh

- Apply boundary conditions.

- Perform simulation

Figure 4 shows the computational domain of the 2D model of the airfoil created in ANSYS workbench for simulation purposes. It consist 60 vertices for creating a computational domain, the length is taken 30 times to that of chord length whereas the width is 20 times the width of an airfoil.

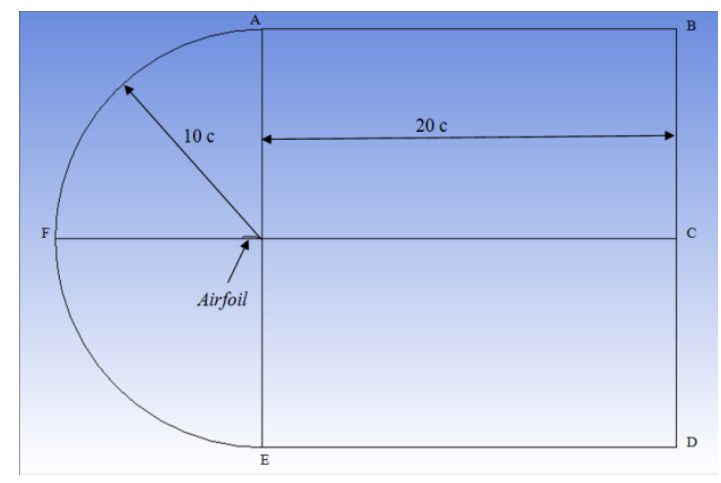

Fig 4. Computational domain of the airfoil

Mesh is conversion of smaller discrete cells of larger domain. Quadratic elements are used for the meshing of the airfoil. The generation of mesh was done in ANSYS workbench. Meshing of a fluid domain of the airfoil is shown in Figure 5. This meshing consists of 40,000 elements, out of which 200 elements are present on the airfoil. Meshing at the far-field is coarse because of the negligible pressure gradient. Figure 6 shows mesh around the airfoil. To capture accurate pressure and velocity distribution around the airfoil, a very fine mesh is provided in the region very close to the airfoil. Computational conditions for $2 \mathrm{D}$ CFD simulation of the airfoil are presented in Table 1.

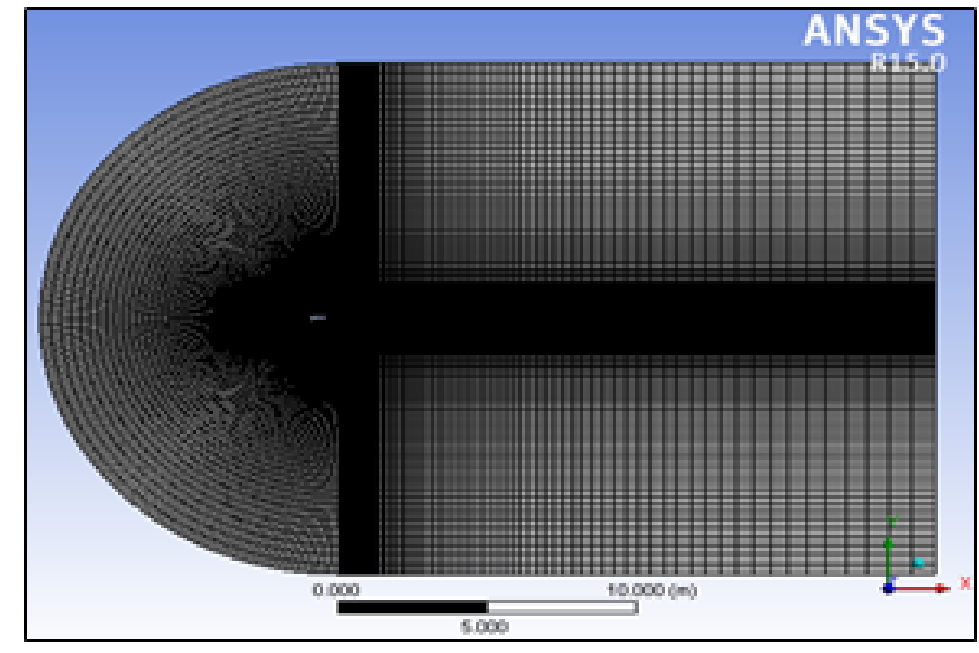

Fig 5. Meshing at fluid domain of airfoil 


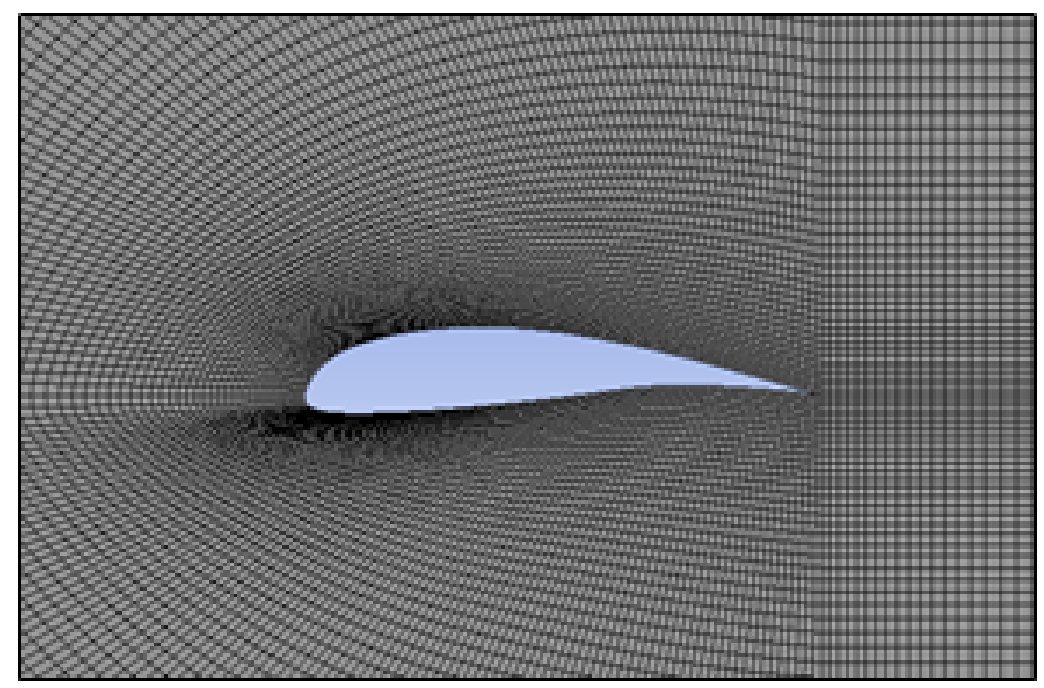

Fig 6. Mesh around the airfoil

Table 1. Computational Conditions for CFD Simulation of the airfoil

\begin{tabular}{ll}
\hline Airfoil & INDTH1293 \\
\hline Fluid Material & Air \\
Simulation Type & Steady Simulation \\
Air Density & $1.225 \mathrm{~kg} / \mathrm{m}^{3}$ \\
Pressure & $101325 \mathrm{~Pa}$ \\
Kinematic Viscosity & $1.467 \times 10^{-5} \mathrm{~m}^{2} / \mathrm{s}$ \\
Temperature & $300 \mathrm{~K}$ \\
Wind speed & $12 \mathrm{~m} / \mathrm{s}$ \\
Fluid Material & Air \\
Simulation Type & Steady Simulation \\
Max Wind Speed & $12 \mathrm{~m} / \mathrm{s}$ \\
Turbulent Model & Spalart-Allmaras (one equation) Model \\
CFD Algorithm & SIMPLEC (Semi-Implicit Method for Pressure Linked Equations-Consistent) \\
Pressure Velocity Coupling & Pressure (Second Order), Momentum (Second Order Upwind) Modified Turbulent Viscosity \\
Boundary Conditions & (Second Order Upwind) \\
\hline
\end{tabular}

\subsection{D CFD Simulation Results}

Simulations are carried out using a pressure-based solver with a structured grid. Figure 7 shows a velocity vector plot along $\mathrm{x}$-direction for different $\mathrm{AOA}$ viz. $0^{\circ}, 3^{\circ}, 9^{\circ}$, and $15^{\circ}$. At $\mathrm{AOA}=0^{\circ}$, separation of boundary layer starts occurring at the leading edge. As the AOA increases, this separation also increases. For the AOA $0^{\circ}$ to $9^{\circ}$ airflow separation occurs on the upper surface near the trailing edge. It is clear from the figure that vortex generation or backflow of stream velocity at the trailing edge is observed as AOA approaches $15^{\circ}$. Vortex generation causes an increase in drag and may reduce the performance of the blade. Hence, it is necessary to keep AOA less for maximizing the lift force and minimizing the drag force. There are two main force components on airfoil first one is lift force (Perpendicular air stream) \& second one is drag force (Parallel and opposite to air stream flow) apart from one lifting moment acting on it. Air flow separation on airfoil glide at trailing edge occurs slowly and increase with AOA. It is cleared from velocity counter for $\mathrm{AOA}=15^{\circ}$, strain drag is very negligible as air flow separation at the trailing edge starts occurring. Strain drag goes on increasing as AOA increase, for $\mathrm{AOA}=15^{\circ}$ it is clear from velocity counter that the strain drag is very high at trailing edge. When velocity gradient is equal to zero, boundary layer separation will start. This flow separation is due to excessive momentum loss near the wall. Formation of small wake region can be observed at the trailing edge. With increase in AOA, boundary layer separation increases near the trailing edge. 

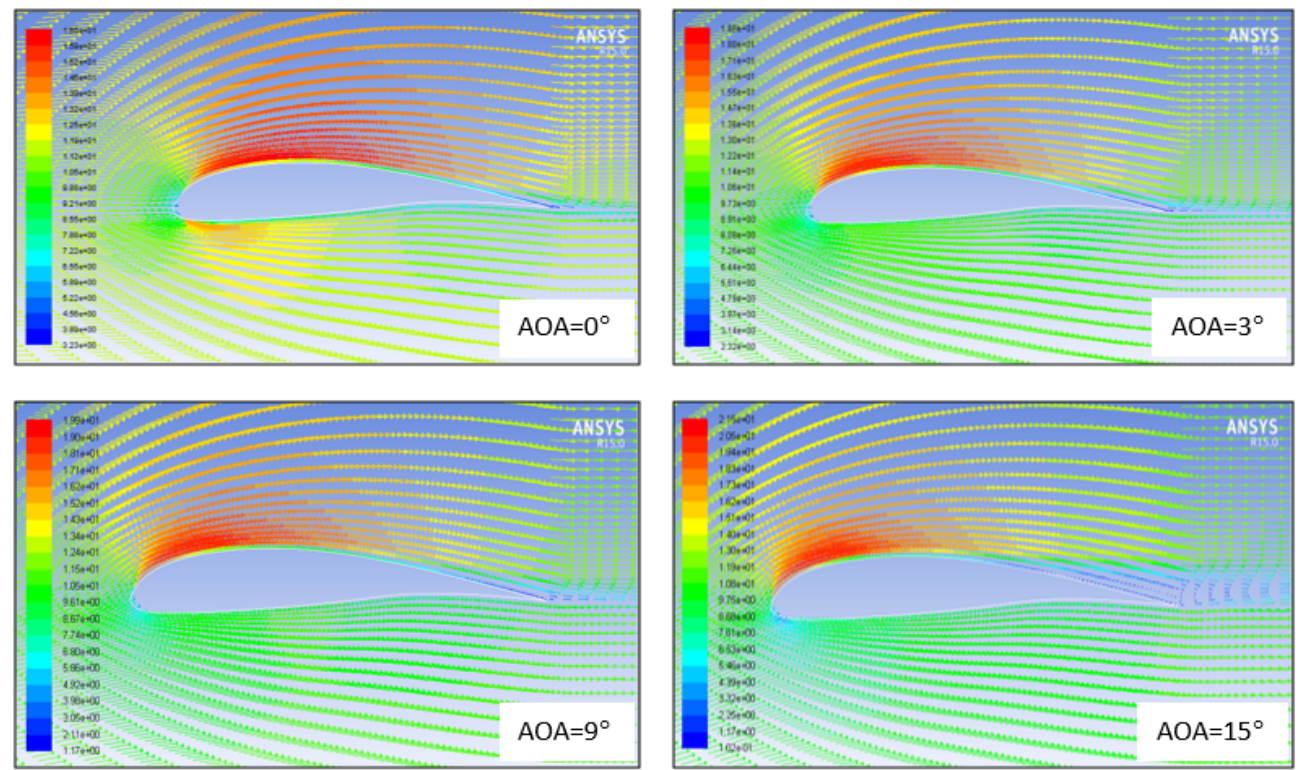

Fig 7. Variation in velocity vector along $\mathrm{x}$-direction for different angles of attack(AOA)

Figure 8 shows the distribution of pressure coefficient at different angles of attack viz. $0^{\circ}, 3^{\circ}, 9^{\circ}$, and $15^{\circ}$. (Pressure coefficient is the ratio of change in pressure force to the inertia force). The maximum pressure coefficient is observed at the leading edge of the airfoil wall on the upper surface. As AOA increases, maximum pressure on the leading edge shifts from the upper surface to the lower surface. It means low pressure on the upper side and high pressure on the lower side of the airfoil wall produces maximum lift. It is noticed that variation in pressure coefficient is maximum at the upper surface of the leading edge for the AOA less than $3^{\circ}$. The direction of pressure distribution on both upper and lower sides is such that it will cause generation of lift. For generation of maximum lift it is convenient to have maximum pressure at the lower side. For AOA ranging between $3^{\circ}-5^{\circ}$, pressure at lower surface of airfoil is more which results into higher lift.
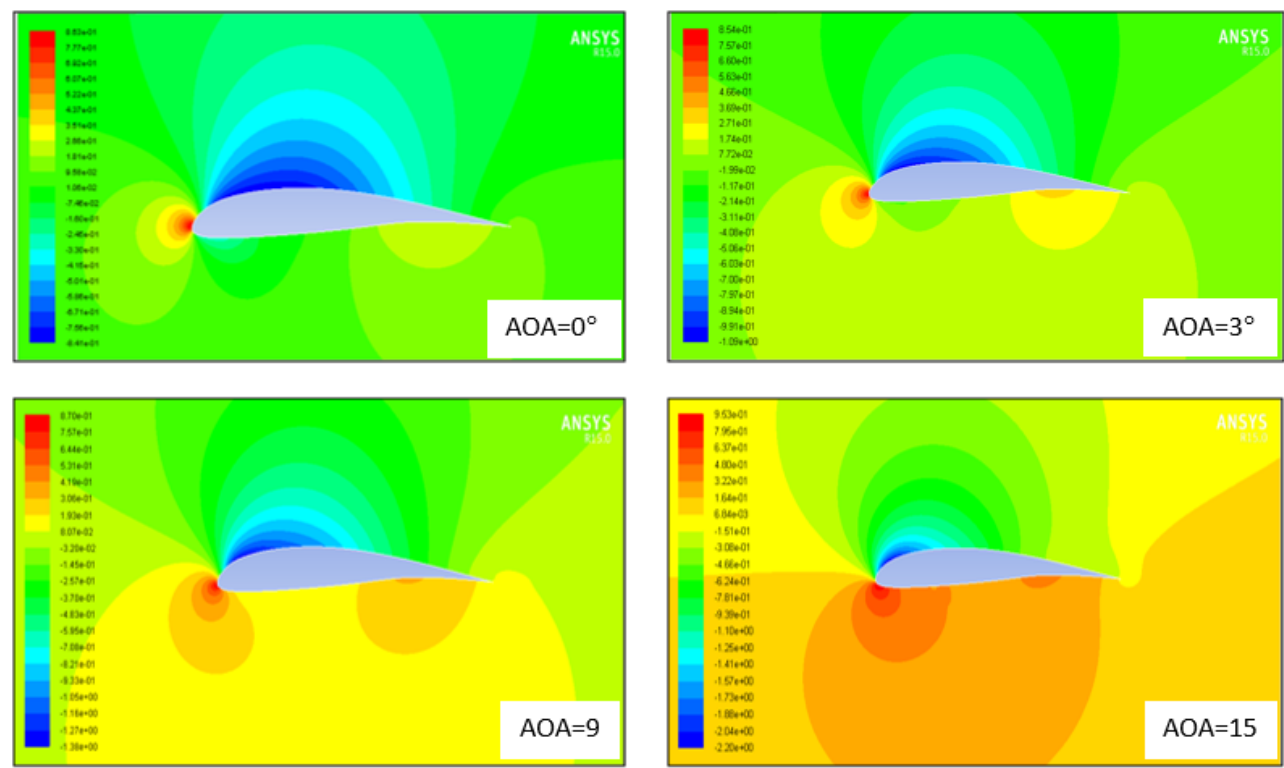

Fig 8. Distribution of pressure coefficient at different angles of attack (AOA) 
It is observed that with increase in $\mathrm{AOA}$, from $0^{\circ}$ to $3.5^{\circ}$, there is an increase in the lift to drag ratio $\left(\mathrm{C}_{L} / \mathrm{C}_{D}\right)$ from 30 to about 40.5 (Figure 9). This is because of increased frontal area from leading edge. As AOA increases beyond $3.5^{\circ}$ there is increase in drag force hence lift to drag ratio $\left(C_{L} / C_{D}\right)$ decrease. From this, we can say AOA has large impact on drag generated. With further increase in AOA, there is a decrease in the lift to drag ratio. Horizontal Axis Wind Turbine (HAWT) is based on principle of maximizes lift. Low Reynolds number aerofoil permits start-up at very low wind speed with less AOA conditions ${ }^{(11)}$.

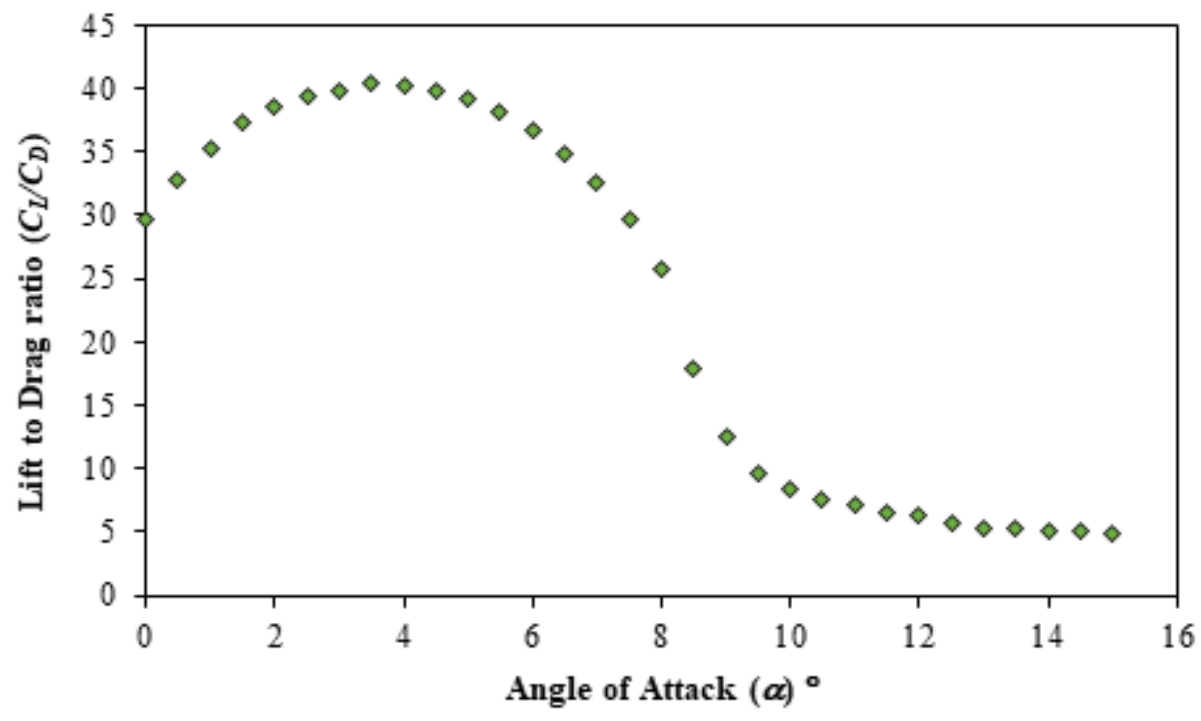

Fig 9. $2 \mathrm{D}$ CFD Simulation Result $\mathrm{C}_{L} / \mathrm{C}_{D}$ ratios Vs. AOA

\section{3D CFD Simulation of an Airfoil}

To increase accuracy in results and to simulate more realistic conditions, a 3D CFD analysis is conducted. 3D CFD simulation consists of airfoil domain generation, fluid domain meshing, meshing around the airfoil, deciding computational conditions, and selecting of turbulence models. For 3D CFD simulation pressure-based solver is used at steady state condition. Computational conditions for 3D CFD simulation are presented in Table 2.

Table 2. Computational Conditions for 3D CFD Simulation of the airfoil

\begin{tabular}{ll}
\hline Solver type & Pressure based \\
\hline Time & Steady \\
Run calculation & Post processing \\
Area & $1 \mathrm{~m}^{2}$ \\
Density & $0.11729 \mathrm{Kg} / \mathrm{m}^{3}$ \\
Temperature & $300 \mathrm{~K}$ \\
Length & $1 \mathrm{~m}$ \\
Enthalpy & 23546.47 \\
Pressure & $10100 \mathrm{Pascal}$ \\
Viscosity & $1.7894 \times 10^{-5} \mathrm{~m}^{2} / \mathrm{s}$ \\
Ratio of specific Heat & 1.4 \\
Velocity formulation & Absolute \\
\hline
\end{tabular}

Figure 10 shows that far-field generation of blade model for 3D CFD simulation, pressure-based solver, and steady time period, absolute velocity formulation conditions were used. Lift coefficient and drag coefficient values for AOA $0^{\circ}$ to $15^{\circ}$ are getting from 3D CFD simulation results. 3D CFD simulation is particularly carried out for lift coefficient and drag coefficient from which we get $C_{L} / C_{D}$ ratio. 


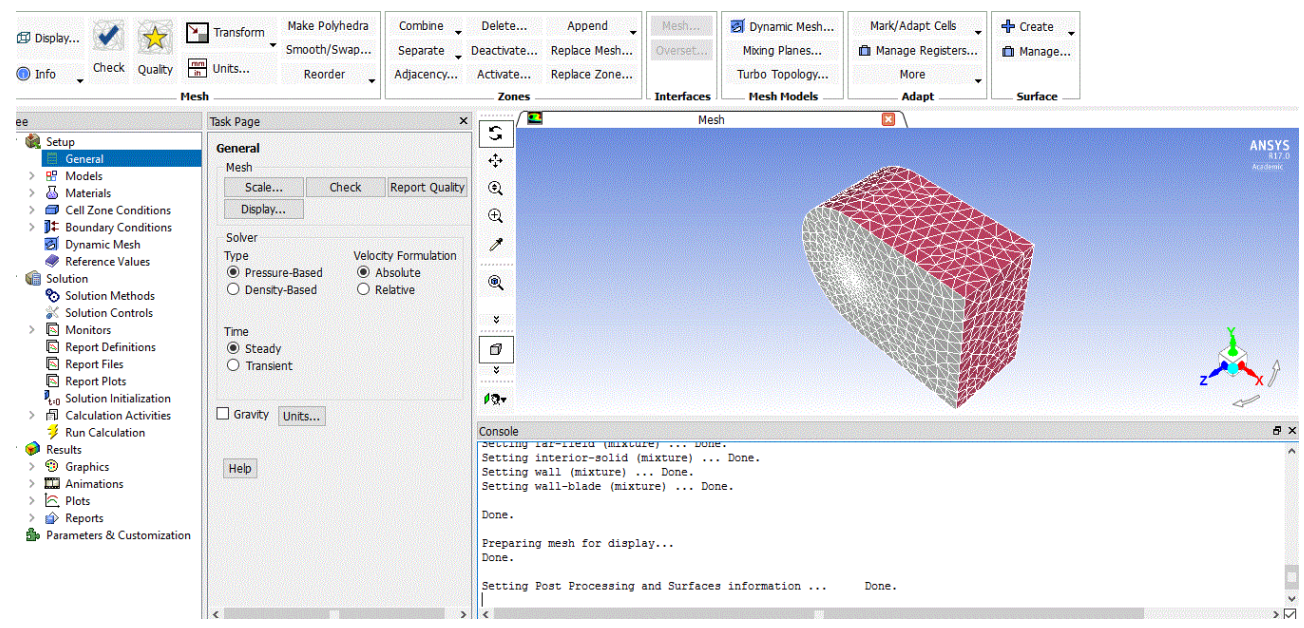

Fig 10. 3D CFD far field generation

3D CFD simulation can predict the flow conditions which are very important for wind turbines. The flow analysis, lift coefficient and drag coefficient are found out at different AOA varying between $0^{\circ}$ to $15^{\circ}$. 3D CFD simulation gives optimum $\mathrm{C}_{L} / \mathrm{C}_{D}$ ratio value of 89.71 for $\mathrm{AOA}$ of $3.5^{\circ}$ (Figure 11). At that point, lift coefficient is 0.9434 and the drag coefficient is 0.0105 .

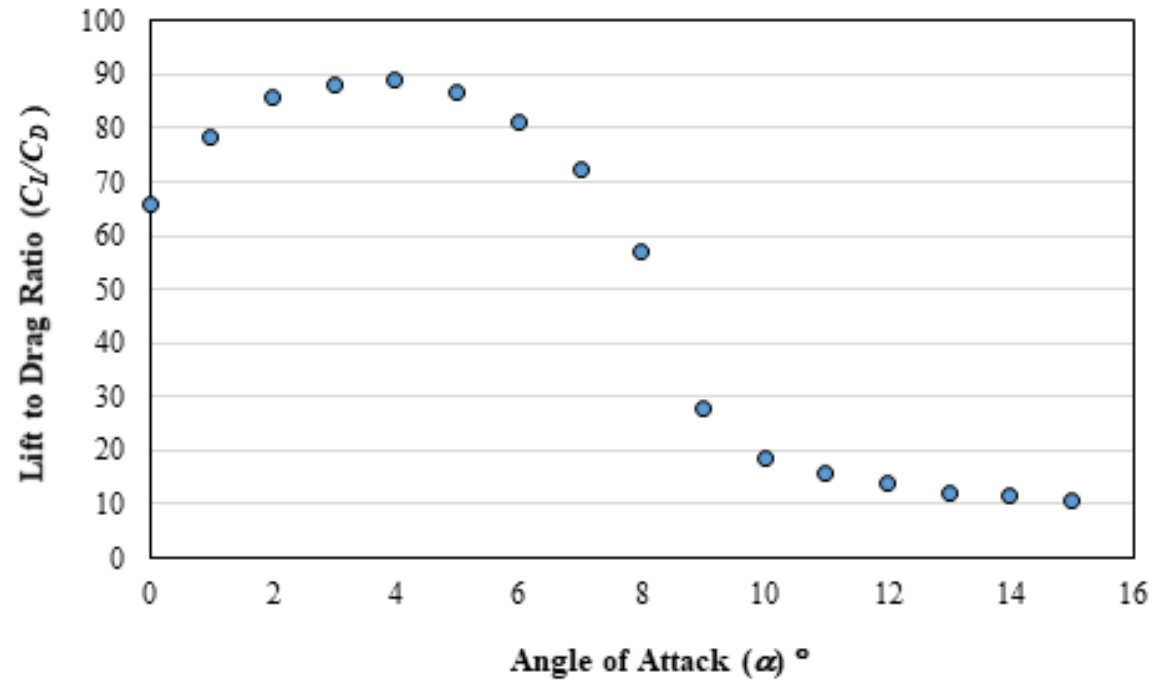

Fig 11. 3D CFD Simulation Result $\mathrm{C}_{L} / \mathrm{C}_{D}$ ratios Vs. AOA

Figure 12 reports a comparison of $\mathrm{C}_{L} / \mathrm{C}_{D}$ ratio at different $\mathrm{AOA}$ for three cases viz. QBlade simulation, $3 \mathrm{D}$ CFD simulation, and experimental results conducted by Dhurpate ${ }^{(23)}$ on the same geometry. The experimental results show that $\mathrm{C}_{L} / \mathrm{C}_{D}$ ratio increases up to maximum value for AOA $5^{\circ}$ and then decreases gradually. The maximum value of the $C_{L} / C_{D}$ ratio is 108.44 for $\mathrm{AOA} 5^{\circ}$ and the lift coefficient and drag coefficient were obtained as 1.122 and 0.0103 respectively. As AOA increases, the grid would not be aligned with the flow anymore which results in a maximum drag coefficient. Drag coefficient values for $0^{\circ}$ to $15^{\circ} \mathrm{AOA}$ are much smaller and for lower AOA it might be difficult for CFD to predict accurate values of the drag coefficient. For $\mathrm{AOA}$ of $0^{\circ}$ to $4^{\circ}$, results obtained from CFD simulations are nearly equal to that of QBlade simulation as well as with the experimental results. QBlade is specially designed software tool for wind turbine airfoil \& blade design. It is the most accurate tool available for simulation of performance of wind turbine blades as compared to any other tool. QBlade simulation is time marching or transient. For AOA above $4^{\circ}$, QBlade results are slightly higher than experimental results. This might be due to various errors occurring in measurement of lift and drag forces during experimentation. 


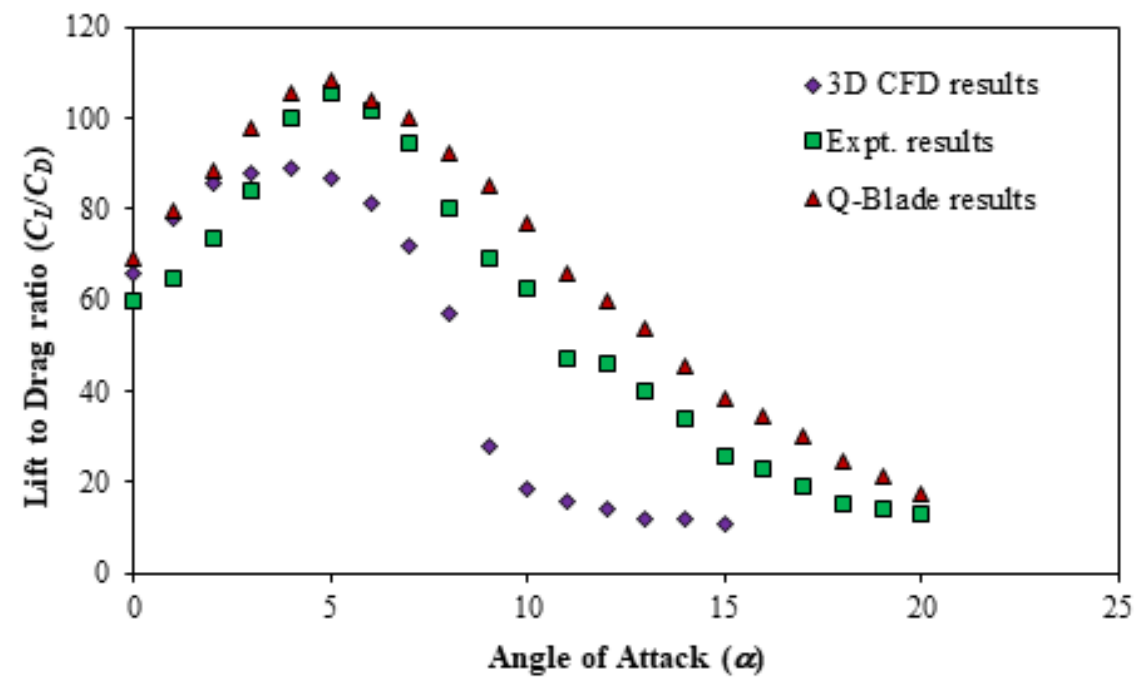

Fig 12. Variation in $C_{L} / C_{D}$ Ratio with $A O A$ during $3 D$ CFD simulation, Q-Blade simulation and during experimentation

The values of the $C_{L} / C_{D}$ ratio are more than double in the case of $3 D$ simulation as compared with $2 D$ simulation (Figure 9). The reasons behind these results are attributed to the more realistic conditions in $3 \mathrm{D}$ simulation as compared with $2 \mathrm{D}$ simulation. Also, in 2D simulation, the body is assumed to be axisymmetric but in the case of an airfoil, this assumption doesn't hold good. In the case of 3D simulation, better quality nodes are obtained. As well as mesh quality is more accurate in the case of 3D simulation as compared with corresponding 2D simulation. Hence, though the solver time increases with 3D simulation, results obtained are more accurate as compared with 2D simulation. With increase in angle of attack, 3D CFD results are found to be lagging much behind the experimental as well as QBlade results. The main reason behind this is transient nature of the flow of wind over the blade. This transient nature is rightly captured by the QBlade simulation as well as by the experimentation. The steady state model of 3D CFD fails to simulate performance of the blade accurately at high angle of attack. This new airfoil is designed for low Reynolds number and permits operation at lower wind speeds. It performs the best at lower angle of attack. As AOA increases there will be increase in both lift and induced drag. Air flow across the upper surface of airfoil becomes detached, resulting loss of lift which causes decrease in lift to drag ratio with increase angle of attack. Koç et al. ${ }^{(32)}$ reported comparison between CFD and QBlade results for small capacity wind turbine at transient condition. QBlade results for power coefficient were slightly higher than that of CFD results for different tip-speed ratios. From the above simulation results it is clear that for a micro-capacity wind turbine, a better range of AOA remains below $8^{\circ}$. From both simulation results, an $\mathrm{AOA}$ of $3^{\circ}$ to $4^{\circ}$ is found to be desirable.

\section{Conclusions}

QBlade software serves as a good tool for airfoil design and predicts results with high accuracy. The maximum power coefficient for the designed airfoil is 0.53 at tip-speed ratio 7 and the maximum lift $/ \mathrm{drag}$ coefficient is 108 at AOA of $5^{\circ}$.

ANSYS CFD Fluent is used for a flow analysis of the designed airfoil. Airfoil is simulated using Spalart-Allmaras (SA) model at different AOA. It is noticed that at AOA less than $3^{\circ}$, pressure coefficient is maximum at the upper surface of the leading-edge resulting in a high value of lift to drag ratio.

3D CFD simulation gives results closer to the experimental results at lower AOA as compared to those with 2D CFD simulations. This might be due to lesser assumptions with 3D simulations and more realistic simulations of the actual conditions. While designing a blade for horizontal axis micro-capacity wind turbine, AOA should be about $3^{\circ}-4^{\circ}$ for maximum power output.

This work reports suitability and limitations of different simulation tools viz. QBlade, 2D CFD and 3D CFD for simulation of performance of small wind turbine blades. Limitations of steady 2D CFD are removed by steady 3D CFD simulation, but it fails to simulate the transient nature of the air flow over the wind turbine blade at higher angle of attacks. This wind-blade interaction is accurately simulated by QBlade. Thus this exercise highlights the application of QBlade software in simulation of performance of small wind turbine blades. It also highlights selection of appropriate initial conditions and turbulence model 
while using CFD tool for simulation of performance of wind turbine blades.

\section{Limitations}

There is discrepancy in 3D CFD results for the wind turbine blade and the experimental results for an airfoil, conducted in the wind tunnel.

\section{Future Scope}

To strengthen the above results, wind tunnel testing of the wind turbine blades, designed using the new airfoil shall be conducted.

\section{References}

1) Ministry of Power, Government of India, Policies \& Publictions, Power Sector at a glance- all India, 2021. . Available from: https://powermin.gov.in/en/ content/power-sector-glance-all-india.

2) Ministry of New \& Renewable Enery, Government of India, Annual Report- 2020-21, Wind Energy: Overview-2019. . Available from: https://mnre.gov. in/img/documents/uploads/file_f-1618564141288.pdf.

3) Rao KR. Wind Energy for Power Generation: Meeting the Challenge of Practical Implementation. Springer International Publishing. 2019.

4) Keith DW, Decarolis JF, Denkenberger DC, Lenschow DH, Malyshev SL, Pacala S, et al. The influence of large-scale wind power on global climate. Proceedings of the National Academy of Sciences. 2004;101(46):16115-16135. Available from: https://doi.org/10.1073/pnas.0406930101.

5) Fiedler BH, Bukovsky MS. The effect of a giant wind farm on precipitation in a regional climate model. Environmental Research Letters. 2011;6(4):45101. Available from: https://iopscience.iop.org/article/10.1088/1748-9326/6/4/045101/meta.

6) Tummala A, Velamati RK, Sinha DK, Indraja V, Krishna VH. A review on small scale wind turbines. Renewable and Sustainable Energy Reviews. 20161;56:1351-1371. Available from: https://doi.org/10.1016/j.rser.2015.12.027.

7) Bukala J, Damaziak K, Kroszczynski K, Krzeszowiec M, Malachowski J. Investigation of parameters influencing the efficiency of small wind turbines. Journal of Wind Engineering and Industrial Aerodynamics. 20151;146:29-38. Available from: https://doi.org/10.1016/j.jweia.2015.06.017.

8) Lee MH, Shiah YC, Bai CJ. Experiments and numerical simulations of the rotor-blade performance for a small-scale horizontal axis wind turbine. Journal of Wind Engineering and Industrial Aerodynamics. 20161;149:17-29. Available from: https://doi.org/10.1016/j.jweia.2015.12.002.

9) Manwell JF, Mcgowan JG, Al R. Wind energy explained: theory, design and application. John Wiley \& Sons. 2010. Available from: http://ee.tlu.edu.vn/ Portals/0/2018/NLG/Sach_Tieng_Anh.pdf.

10) Rodrigues RM, Piper JD, Bhattacharya SS, Wilson SA, Birzer CH. Development of guidelines for the construction of wind turbines using scrap material. Procedia engineering. 20161;159:292-299. Available from: https://doi.org/10.1016/j.proeng.2016.08.181.

11) Singh RK, Ahmed MR. Blade design and performance testing of a small wind turbine rotor for low wind speed applications. Renewable Energy. 20131;50:812-819. Available from: https://doi.org/10.1016/j.renene.2012.08.021.

12) Ali A, Chowdhury H, Loganathan B, F A. An aerodynamic study of a domestic scale horizontal axis wind turbine with varied tip configurations. Procedia Engineering. 2015;105(1):757-762. Available from: https://doi.org/10.1016/j.proeng.2015.05.067.

13) Pourrajabian A, Ebrahimi R, Mirzaei M. Applying micro scales of horizontal axis wind turbines for operation in low wind speed regions. Energy Conversion and Management. 20141;87:119-127. Available from: https://doi.org/10.1016/j.enconman.2014.07.003.

14) Ozgener O. A small wind turbine system (SWTS) application and its performance analysis. Energy Conversion and Management. 20061;47(11-12):13261337. Available from: https://doi.org/10.1016/j.enconman.2005.08.014.

15) Ameku K, Nagai BM, Roy JN. Design of a $3 \mathrm{~kW}$ wind turbine generator with thin airfoil blades. Experimental Thermal and Fluid Science. 20081;32(8):17231730. Available from: https://doi.org/10.1016/j.expthermflusci.2008.06.008.

16) Xie W, Zeng P, Lei L. Wind tunnel experiments for innovative pitch regulated blade of horizontal axis wind turbine. Energy. 20151;91:1070-1080. Available from: https://doi.org/10.1016/j.energy.2015.08.111.

17) Monteiro JP, Silvestre MR, Piggott H, Andre JC. Wind tunnel testing of a horizontal axis wind turbine rotor and comparison with simulations from two Blade Element Momentum codes. Journal of Wind Engineering and İndustrial Aerodynamics. 20131;123:99-106. Available from: https: //doi.org/10.1016/j.jweia.2013.09.008.

18) Choubey A, Baredar P, Choubey N. Power Optimization of NACA 0018 Airfoil Blade of Horizontal Axis Wind Turbine by CFD Analysis. International Journal of Energy Optimization and Engineering. 2020;(1):122-139. doi:10.4018/IJEOE.2020010104.

19) Ani VA. Optimal energy system for single household in Nigeria. International Journal of Energy Optimization and Engineering. 2013;1(3):16-41. doi:10.4018/ijeoe.2013070102.

20) Reddy KP, Rao MV. Modelling and simulation of hybrid wind solar energy system using MPPT. Indian journal of Science and Technology. 2015;8(23).

21) Surve ML. A Comprehensive Review of Developing Horizontal Axis Wind Turbine Rotor Blade for Domestic Applications. International Research Journal of Engineering and Technology. 2017;4(6):984-90. Available from: https://www.irjet.net/archives/V4/i6/IRJET-V4I6183.pdf.

22) Marten D, Wendler J, Pechlivanoglou G, Nayeri CN, Co P. QBLADE: an open source tool for design and simulation of horizontal and vertical axis wind turbines. International Journal of Emerging Technology and Advanced Engineering. 2013;3(3):264-269.

23) Dhurpate P. Numerical Analysis of Different Airfoils Using QBlade Software. Imperial Journal of Interdisciplinary Research. 2016;2(6). Available from: http://www.onlinejournal.in/IJIRV2I6/264.pdf.

24) Pourrajabian A, Dehghan M, Javed A, Wood D. Choosing an appropriate timber for a small wind turbine blade: A comparative study. Renewable and Sustainable Energy Reviews. 2019;100:1-8. doi:10.1016/j.rser.2018.10.010.

25) Birajdar M, Kale S, Sapali SN. Effects of design parameters on aerodynamic performance of new profile small wind turbine blades. In: InASME International Mechanical Engineering Congress and Exposition 2015. American Society of Mechanical Engineers. 2015. Available from: https://doi. org/10.1155/2019/6405153.

26) Khalil Y, Tenghiri L, Abdi F, Bentamy A. Efficiency of a small wind turbine using BEM and CFD. InIOP Conference Series: Earth and Environmental Science. 2018;1(161). doi:10.1088/1755-1315/161/1/012028. 
27) Tasneem Z, Noman A, Das A, Saha SK, Islam DK, Ali MR, et al. An analytical review on the evaluation of wind resource and wind turbine for urban application: Prospect and challenges. Developments in the Built Environment. 2020;(100033). Available from: https://doi.org/10.1016/j.dibe.2020.100033.

28) Bangga G. Comparison of blade element method and CFD simulations of a 10 MW wind turbine. Fluids. 2018;3:73. doi:10.3390/fluids3040073.

29) Ansys Fluent Fluid Simulation Software. ANYS Inc. 2018. Available from: https://www.ansys.com/en-in/products/fluids/ansys-fluent.

30) Jensenjj T. CFD Study of a 10 MW Offshore Horizontal Axis Wind Turbine Blade. Trondheim, Norway. 2011. Available from: https://ntnuopen.ntnu.no/ ntnu-xmlui/handle/11250/246425.

31) ANSYS FLUENT 12.1 Documentation, Transport Equation for the Spalart-Allmaras Model. ANSYS, Inc. 2009. Available from: https://www.afs.enea.it/ project/neptunius/docs/Fluent/html/th/node50.htm.

32) Koç E, Günel O, Yavuz T. Comparison of Qblade and CFD results for small-scaled horizontal axis wind turbine analysis. 2016 IEEE International Conference on Renewable Energy Research and Applications (ICRERA). 2016;p. 204-209. doi:10.1109/ICRERA.2016.7884538. 